Akreditasi KEMENRISTEKDIKTI, Nomor: 148/M/KPT/2020
http://iurnal.stkippersada.ac.id/iurnal/index.php/voX

\title{
PENGEMBANGAN LABORATORIUM VIRTUAL GEOGRAFI UNTUK KULIAH KERJA LAPANGAN DI ERA PANDEMI COVID-19
}

\author{
Mohamad Arif ${ }^{1}$, Rudi Hartono ${ }^{2}$, Satti Wagistina $^{3}$, \& Dicky Arinta ${ }^{4}$ \\ 1,2,3,4 Ilmu Sosial, Universitas Negeri Malang \\ Email: mohamad.arif@um.ac.id ${ }^{l}$, rudi.hartono.fis@um.ac.id ${ }^{2}$, satti.wagistina.fis@um.ac.id $^{3}$, \\ dickyarinta.b@gmail.com ${ }^{4}$
}

INFO ARTIKEL
Riwayat Artikel:
Menerima $: 15$ September 2021
Revisi $\quad: 17$ September 2021
Diterima $\quad: 14$ Oktober 2021

\section{Kata Kunci:}

Pengembangan, Laboratorium Virtual, Video Virtual 360 derajat

\section{Keywords:}

Development, Virtual Lab, 360 degree Virtual Video

\section{Korespondensi:}

Mohammad Arif

Universitas Negeri Malang

Email:

mohamad.arif@um.ac.id

\begin{abstract}
ABSTRAK
Laboratorium geografi Fakultas Ilmu Sosial Universitas Negeri Malang di masa pandemi covid-19 tidak bisa beroperasi seperti hari normal biasa, karena mahasiswa diwajibkan untuk belajar dari rumah. Berdasarkan surat edaran rektor Universitas Negeri Malang Nomor 17.12.70/UN32.IlSEl2020 tentang penyelenggaraan pembelajaran pada semester genap tahun akademik 20202021 di masa pandetni Covid-19. Laboratorium virtual bisa menjadi solusi praktikum kuliah lapangan di tengah wabah pandemi covid-19. Salah satu teknologi modern yang dapat digunakan untuk di implementasikan pada kasus ini adalah melalui video virtual 360/virtual reality yang mengacu pada konsep dimana semua objek seakan dapat dijelajahi seperti dunia aslinya. Video virtual 360 derajat menjadi solusi pengganti kuliah lapangan karena dapat memperlihatkan teknik pengukuran di lapangan dengan kondisi yang nyata. Tujuan uji coba adalah untuk uji efektifitas pengembangan laboratorium virtual video 360 derajat. Metodologi penelitian model Dick \& Carrey, dengan di sederhanakan menjadi tujuh prosedur pengembangan. Subjek uji coba adalah mahasiswa Jurusan Geografi FIS UM.. Dan ditinjau dari rata rata total validasi ahli media dan materi video virtual 360 berbasis multimedia interaktif dinilai hasil validasi ahli desain diperoleh nilai kevalidan mencapai 78,5\% hal tersebut masuk dalam kriteria $(71 \%-85 \%)$ dan masuk dalam kriteria valid dan layak digunakan untuk pembelajaran di kelas tidak perlu revisi.
\end{abstract}

\section{ABSTRACT}

The geography laboratory of the Faculty of Social Sciences, State University of Malang during the COVID-19 pandemic cannot operate as normal, because students are required to study from home. Based on the circular letter of the Chancellor of the State University of Malang Number 17.12.70/UN32.IlSEl2020 regarding the implementation of learning in the even semester of the 2020-2021 academic year during the Covid-19 pandetni period. Virtual laboratories can be a practical solution for field lectures in the midst of the COVID-19 pandemic. One of the modern technologies that can be used to implement in this case is through virtual video 360/virtual reality which refers to the concept where all objects can be explored like the real world. 360-degree virtual video is a solution to replace field lectures because it can show measurement techniques in the field with real conditions. The purpose of the trial is to test the effectiveness of developing a 360-degree video virtual laboratory. The research methodology of the Dick \& Carrey model is simplified into seven development procedures. The test subjects were students of the Department of Geography, FIS UM. And in terms of the average total validation of media experts and interactive multimedia-based 360 virtual video materials, the validation results of design experts obtained a validity value of $78.5 \%$, it was included in the criteria $(71 \%-85 \%)$ and is included in the valid criteria and is suitable for use in classroom learning, no revision is needed. 


\section{PENDAHULUAN}

Pandemi covid-19 mengakibatkan perubahan social yang terjadi secara tiba-tiba dan tidak dikendaki oleh masyarakat khususnya di bidang Pendidikan (Kantamneni, 2020). Pandemi Covid19 telah mempengaruhi semua sistem pendidikan dari tingkat pra-sekolah, sekolah dasar, sekolah menengah hingga lembaga perguruan tinggi (Lièvre et al., 2020). Pembelajaran secara daring adalah suatu realita yang harus dihadapi oleh peserta didik maupun pendidik seiring dengan perkembangan IPTEK/teknologi komunikasi. Banyaknya platform pembelajaran daring yang dapat diterapkan akhir-akhir ini, mengubah kebiasaan dalam dunia pendidikan (Ermila Hendriyani \& Novi, 2020).

Pembelajaran daring merupakan satu-satunya cara untuk tetap terlaksananya pembelajaran di masa pandemi. Berbagai inovasi pembelajaran terus dikembangkan guna memenuhi tuntutan untuk tetap terlaksananya pengajaran meskipun tidak bertemu secara langsung. Sistem informasi teknologi jarak jauh dengan daring (online) dalam pendidikan yang harus disiapkan untuk menjalankan metode learning from home (Ramdani et al., 2020). Salah satu alternatif yang dapat dilakukan adalah dengan membuat video virtual 360 atau virtual reality sehinga praktik lapangan bisa dilakukan secara daring. Jurusan geografi yang identik dengan praktikum baik lapangan maupun laboratorium maka sangat diperlukan laboratorium virtual saat pembelajaran daring.

Laboratorium geografi Fakultas Ilmu Sosial Universitas Negeri Malang di masa pandemi covid-19 tidak bisa beroperasi seperti hari normal biasa, karena mahasiswa diwajibkan untuk belajar dari rumah. Berdasarkan surat edaran rektor Universitas Negeri Malang Nomor 17.12.70/UN32.IlSEl2020 tentang penyelenggaraan pembelajaran pada semester genap tahun akademik 2020-2021 di masa pandetni Covid-19. Surat edaran tersebut menjelaskan bahwa proses belajar mengajar untuk teori dilaksanakan secara daring dan pelaksanaan praktikum dilakukan secara luring dengan ketentuan bahwa maksimal $25 \%$ dari jumlah pertemuan.

Kegitan praktikum di laboratorium geografi saat pandemi menjadi sangat terbatas. Imbas dari pandemi di dunia pendidikan, mengubah pola pembelajaran kelas yang dilaksanakan secara daring dan praktikum laboratorium ataupun lapangan menjadi kegiatan praktikum virtual dan mandiri ((Ermila Hendriyani \& Novi, 2020).
Praktikum lapangan merupakan pembelajaran yang sangat penting, terutama di bidang ilmu geografi. Geografi sebagai ilmu yang erat kaitanya dengan kajian lapangan maupun laboratorium sebagai wujud nyata dari teoritis dalam mengembangkan intelegensi dan keilmuanya. Selain itu, kelebihan praktikum dapat membuat peserta didik berlatih secara trial and error, dan mengulang kembali kegiatan/tindakan sampai totalitas terampil. Kegiatan praktikum menjadi bekal yang nyata untuk membekali lulusan geografi di dunia kerja.

Laboratorium virtual bisa menjadi solusi praktikum kuliah lapangan di tengah wabah pandemi covid-19. Salah satu teknologi modern yang dapat digunakan untuk di implementasikan pada kasus ini adalah melalui video virtual 360/virtual reality yang mengacu pada konsep dimana semua objek seakan dapat dijelajahi seperti dunia aslinya, dapat berjalan menelusuri ke segala arah, melihat ke segala arah, memutar, dan menjelajahi sekelilingnya (Ramdani et al., 2020).

Dengan menggunakan video virtual 360 akan sangat membantu mahasiswa untuk melaksanakan praktikum lapangan secara virtual melalui video yang meliputi view lokasi penelitian (pantai malang selatan), lokasi penelitian yang diperoleh dari citra satelit google earth, pengukuran lapangan dan pengolahan data lapangan yang tersusun rapi di dalam video virtual. Pengembangan laboratorium virtual video 360 diharapkan dapat membuat mahasiswa belajar lebih mudah. Keunggulan media pembelajaran yang dikembangkan adalah dapat menyajikan materi secara menarik dan mudah dipahami serta menyajikan contoh-contoh permasalahan yang bervariasi dengan tingkat kesulitan yang berbedabeda.

\section{Tujuan Pengembangan Laboratorium Virtual}

Tujuan dari pengembangan laboratorium virtual geografi adalah untuk mengatasi permasalahan kegiatan praktikum di masa pandemi covid-19. Tujuan khusus dari pengembangan ini meliputi:

a. Produksi video virtual 360 derajad/ virtual realty

b. Menguji validitas dan efektifitas video virtual 360 derajad untuk pembelajaran praktikum virtual kuliah lapangan geografi.

\section{Spesifikasi Produk}

Penjelasan spesifikasi produk yang dikembangankan adalah untuk mendeskripsikan 
pengembangan laboratorium virtual geografi dengan menggunakan video virtual 360 derajat penjelasan secara rinci sebagai berikut:

Video virtual 360 derajat virtual tour: pengukuran evaluasi pantai untuk kegiatan pariwisata pada tabel 1 dibawah.

Tabel 1 Spesifikasi Produk

\begin{tabular}{|c|c|}
\hline NoPoin & Keterangan \\
\hline 1 Pembukaan & View pantai \\
\hline \multirow{3}{*}{2 Isi } & Penentuan lokasi pantai \\
\hline & $\begin{array}{ll}\text { Pembacaan } & \text { instrument } \\
\text { pengukuran }\end{array}$ \\
\hline & $\begin{array}{l}\text { Melakukan pengukuran untuk } \\
\text { evaluasi pantai }\end{array}$ \\
\hline 3 Penutup & Tabulasi data hasil pengukuran \\
\hline
\end{tabular}

\section{Pentingnya Penelitian dan Pengembangan}

Hasil dari penelitian dan pengembangan ini diharapkan dapat memberikan manfaat yaitu: Menyediakan Video virtual pengganti praktik kuliah lapangan mahasiswa geografi di masa pandemi covid-19 dan juga mengembangkan laboratorium geografi agar bisa tetap melakukan pelayanan meskipun tidak ada aktifitas pembelajaran secara langsung (luring).

\section{KAJIAN PUSTAKA \\ Laboratorium Virtual}

Laboratorium sebagai tempat praktikum mahasiswa merupakan garda terdepan dalam meningkatkan kompetensi yang dimiliki mahasiswa (Yusuf et al., 2015). Pengelolaan pendidikan terutama kaitannya dengan laboratorium identik dengan persoalan-persoalan yang seringkali cukup pelik. Permasalahan sumber daya seringkali menjadi kendala dalam pengelolaan jalannya pendidikan di laboratorium. Apalagi di masa pandemi seperti sekarang ini laboratorium memiliki kendala dalam hal pelayan terhadap mahasiswa yang akan melakukan praktikum. Idealnya seorang mahasiswa mendapatkan fasilitas yang maksimal dalam praktek yang harus dilakukan dalam proses belajar, namun dimasa pandemi ini mahasiswa harus melakukan praktikum secara daring (Mastuty, 2020). Kegiatan praktik lapangan sangat sulit dilakukan karena terkendala oleh peraturan dan perizinan. Masa pandemi menjadikan kegiatan sosial menjadi sangat terganggu hal tersebut berimbas secara langsung terhadap kegiatan prktikum lapangan mahasiswa. Hambatan-hambatan itulah yang harus disiasati perguruan tinggi khususnya pengelola laboratorium untuk dapat berjalannya pelayanan laboratorium meski dalam kondisi pandemi (Kusumaningsih, Y.R, Iswahyudi, C., \& Susanti, 2014).

Laboratorium virtual merupakan laboratorium yang ada di dalam perangkat computer/laptop yang digunakan mahasiswa dalam melakukan eksperimen dengan aplikasi tanpa memerlukan adanya alat-alat laboratorium nyata. Bastian and Idrus, (2019) menyatakan bahwa laboratorium virtual adalah suatu bentuk objek multimedia yang interaktif dan bisa dikendalikan. Media laboratorium virtual adalah suatu media berbasis komputer berupa simulasi kegiatan praktikum seperti halnya kegiatan eksperimen di laboratorium sebenarnya. mahasiswa dapat mengembangkan kemampuan dalam mengoperasikan komputer dan sudah mengenal pentingnya pendidikan yang menjadi masalah dalam suatu proses pemecahan masalah di dalam kehidupan.

\section{Video Virtual 360}

Perkembangan teknologi yang semakin pesat saat ini, sehingga memunculkan banyak inovasi baru dari teknologi, salah satu inovasi yang berkembang saat ini adalah video 360 derajat. Teknologi ini sudah banyak digunakan dalam salah satu cara memvisualisasikan suatu kegiatan dengan tampilan yang dapat menampilkan keseluruhan sudut pandang yang ada di sekitar sehingga dapat melihat suatu tempat seperti nyata dengan video virtual. Bao et al., (2017) menyatakan video 360 merupakan video yang dibuat oleh system kamera yang secara bersamaan merekam arah secara keseluruhan dengan rotasi 360 derajat, user dapat menggeser dan memutar sudut pandang 360 video untuk menonton dari sudut yang berbeda

Ada beberapa riset termutakhir yang memanfaatkan teknologi video virtual 360/ Virtual Reality sebagai perangkat pembelajaran, khususnya pada pembelajaran praktikum.

Hal ini memang awalnya kebanyakan ditujukan bukan karena kondisi pandemi, melainkan untuk meminimalisasi resiko dan menjadikan praktikum dengan VR lebih ekonomis, karena perangkat praktikum yang dibuat dalam bentuk 3D sedemikian rupa ini bisa diduplikasi sebanyak mungkin sesuai kebutuhan institusi pendidikan yang bersangkutan (Zikky et al., 2020). Video 360 derajat adalah kecanggihan 
komputer yang dapat merekam setiap sisi secara 360 derajat dari atas, bawah dan setiap sisi yang ingin dilihat, serta memiliki kemampuan untuk melibatkan keseluruhan persepsi inderawi manusia : penglihatan, suara, penciuman, sentuhan dan rasa. Virtual Reality Photography merupakan sebuah teknik dalam menghasilkan sebuah foto $360^{\circ}$ (Putra, 2020). Pengguna video ini mendapatkan kemampuan untuk masuk ke dalam bingkai video dan mengontrol tampilan pengalaman yang mereka dapatkan.

\section{Pengertian Geografi}

Pakar Geografi pada Seminar dan Lokakarya Peningkatan Kualitas Pengajaran Geografi di Semarang tahun 1988, telah merumuskaan konsep Geografi sebagai berikut: "Geografi adalah ilmu yang mempelajari persamaan dan perbedaan fenomena geosfer dengan sudut pandang kelingkungan dan kewilayahan dalam konteks keruangan (Basse et al., 2014). Bahan kajian Geografi secara garis besar, dikelompokkan ke dalam dua bagian, yaitu yang mempelajari fenomena-fenomena alam (Geografi Fisik) dan yang mempelajari fenomenafenomena nonalami yaitu manusia dan kebudayaannya (Geografi Manusia atau Human Geography) (Hagerstrand, 2019)

\section{Pengembangan Model Dick and Carey}

Model Dick and Carey dapat digunakan untuk menguji keefektifan produk. Metode penelitian dan pengembangan digunakan untuk menghasilkan produk tertentu dan menguji keefektifan produk tersebut (Martanti \& Winarni, 2020). Selain itu, model pengembangan Dick and Carey yang digunakan dalam penelitian ini diadaptasi sesuai kebutuhan pengembangan. Menurut (Rosita \& Leonard, 2015), Penelitian dengan menggunakan model Dick dan Carey yang berisi kegiatan evaluasi formatif disebut sebagai kegiatan validasi produk.

Model Dick dan Carey memiliki beberapa langkah. Langkah-langkah dalam model (Dick dan Carey dalam Molenda, (2015), meliputi: a) Menilai kebutuhan untuk mengidentifikasi tujuan, b) Melakukan analisis instruksional, c) Menganalisis peserta didik dan konteks, d) Menulis tujuan kinerja, e) Mengembangkan instrumen penilaian, f) Mengembangkan strategi instruksional, g) Mengembangkan dan memilih bahan pembelajaran, h) Merancang dan melakukan evaluasi formatif instruksi, i) Merevisi evaluasi formatif, j) Melakukan evaluasi sumatif.
Pemilihan Model Dick \& Carey sebagai model yang digunakan untuk mengembangkan pedoman kuliah kerja lapangan karena beberapa alasan; Pertama, Model rancangan Dick \& Carey menggunakan pendekatan sistem dengan langkahlangkah yang lengkap dan dapat digunakan untuk merancang pembelajaran secara klasikal maupun individual (Clayton \& Abbass, 2019). Kedua, Model Dick \& Carey digunakan dengan dasar pemikiran bahwa dosen bertugas sebagai perancang pembelajaran, pelaksana, dan penilai kegiatan hasil pembelajaran (Almazyad \& Alqarawy, 2020). Ketiga, model Dick \& Carey memungkinkan untuk mengelaborasi materi menjadi lebih mudah, Lee et al., (2015) mengungkapkan bahwa dengan melakukan tahapan-tahapan elaborasi akan membuat penyajian materi bergerak dari umum ke khusus. Keempat, Model Dick \& Carey memenuhi empat karakteristik utama yang harus ada dalam pengembangan pembelajaran, yakni: (a) mengacu pada tujuan, (b) terdapat keserasian dengan tujuan, (c) sistematik, (d) berpedoman pada evaluasi (Almazyad \& Alqarawy, 2020). Kelima, Model Dick \& Carey dapat digunakan utuk mengembangka pemebelajaran pada ranah informasi verbal, keterampilan intelektual, keterampilan pisikomotor, dan sikap.

\section{METODE PENELITIAN \\ Model Pengembangan}

Model konseptual yang digunakan dalam pengembangan bahan ajar geografi ini, yaitu model Dick \& Carrey. Model tersebut tidak sepenuhnya diadopsi, tetapi diadaptasikan atau disesuaikan dengan grand design penelitian. Penyesuaian diwujudkan dalam bentuk penyederhanaan prosedur pengembangan (Friedman \& Schneider, 2018). Prosedur pengembangan Model Dick \& Carey terdiri dari sepuluh langkah. Prosedur tersebut disederhanakan menjadi tujuh langkah pengembangan yakni: (1) identify intructional goals (mengidentifikasi tujuan), (2) conduct instructional analysis (menganalisis pembelajaran), (3) develop instructional strategy (mengembangkan strategi pembelajaran), (4) develop and select materials (mengembangkan dan memilih materi pembelajaran), (5) design and conduct formative evaluation of instruction (merancang dan melaksanakan evaluasi formatif pembelajaran), (6) revise instruction (merevisi pembelajaran), (7) design and conduct summative evaluation (mendesain dan melakukan evaluasi 
sumatif). Subjek uji coba adalah mahasiswa Jurusan Geografi FIS UM..

\section{Prosedur Pengembangan}

Prosedur pengembangan tersebut tidak seluruhnya digunakan dalam penelitian. Sepuluh langkah pengembangan dimodifikasi dan disederhanakan menjadi tujuh kegiatan (Sapri et al., 2019). Alasan yang mendasari pemodifikasian dan penyederhanaan tersebut, diuraikan sebagai berikut.

a. Pengembangan ini bertujuan untuk menghasilkan produk berbentuk video virtual 360

b. Prosedur uji coba produk berbentuk video tidak membutuhkan rumusan strategi yang rumit, seperti uji coba model pembelajaran. Prosedur uji coba kepada mahasiswa dilakukan dengan eksplanasi petunjuk pengoperasian video, kemudian respon mahasiswa dikumpulkan dengan menggunakan angket.

c. Tahapan ujicoba pengembangan ini dibatasi sampai tahap formative evaluation. Pembatasan tahapan uji coba didasarkan pada subtansi pengukuran evaluasi lahan pantai untuk kegitan pariwisata. Uji coba dilakukan dengan cara menerapkan produk dalam pembelajaran dan melibatkan kelompok kecil siswa.

Secara spesifik, alur prosedur pengembangan dalam penelitian diilustrasikan dalam gambar berikut.

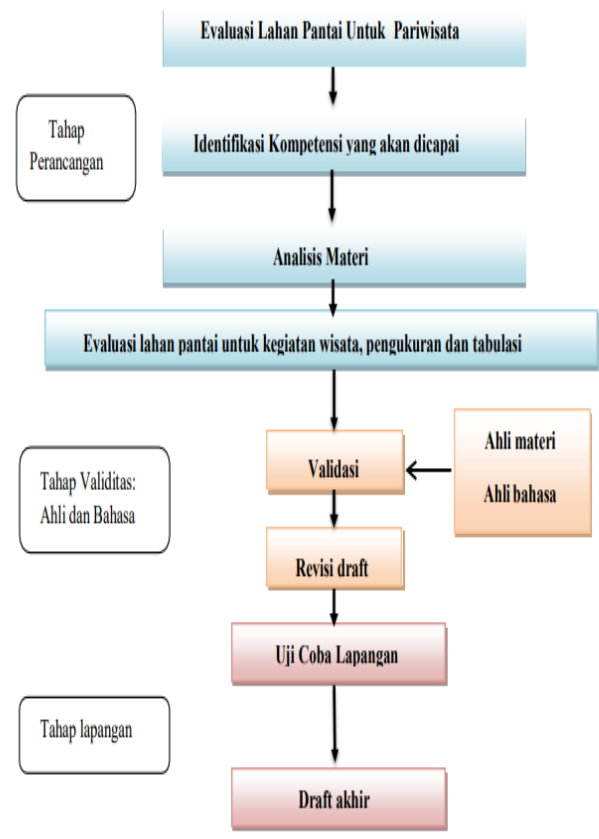

\section{Gambar 1. Alur Pengembangan Laboratorium virtual geografi untuk kuliah kerja lapangan dengan video virtual 360 derajat}

\section{Instrumen Pengumpulan Data}

Instrumen yang digunakan untuk mengumpulkan data uji coba lapangan terdiri dari dua jenis, yaitu angket dan soal. Instrumen berupa angket untuk mengumpulkan data respon mahasiswa. Angket tersebut diberikan kepada siswa saat proses pembelajaran dengan menggunakan video virtual 360. Instrumen berupa soal untuk mengumpulkan data hasil belajar mahasiswa. Soal tersebut diberikan kepada mahasiswa setelah proses penerapan video virtual 360 (Hamilton et al., 2021). Berikut ini struktur makro pertanyaan dalam angket diuraikan dalam tabel 2 dibawah.

\section{Tabel 2 Struktur Instrumen Angket}

\begin{tabular}{|c|c|}
\hline Aspek & Fokus Pertanyaan \\
\hline \multirow{3}{*}{$\begin{array}{l}\text { Substansi } \\
\text { materi }\end{array}$} & Kualitas materi (kedalaman dan keluasan) \\
\hline & Akurasi materi (kebenaran contoh) \\
\hline & Sistematika (keruntutan penjabaran) \\
\hline \multirow[t]{3}{*}{ Kebahasaan } & $\begin{array}{l}\text { Kesesuaian dengan kaidah bahasa } \\
\text { (kebakuan kata dan pemilihan istilah } \\
\text { yangmudah dipahami) }\end{array}$ \\
\hline & $\begin{array}{l}\text { Konsistensi struktur paragraf (keterbacaan } \\
\text { pokok pikiran) }\end{array}$ \\
\hline & $\begin{array}{l}\text { Ketercernaan penjabaran (kelugasan } \\
\text { penjabaran) }\end{array}$ \\
\hline \multirow[t]{3}{*}{ Media } & Substansi (kesesuain ilustrasi dengan materi) \\
\hline & $\begin{array}{l}\text { Visualisasi (kemudahan ilustrasi untuk } \\
\text { diamati) }\end{array}$ \\
\hline & $\begin{array}{l}\text { Komunikatif (kemudahan ilustrasi untuk } \\
\text { dipahami maknanya) }\end{array}$ \\
\hline \multirow{4}{*}{$\begin{array}{l}\text { Tanpilan } \\
\text { Layout }\end{array}$} & Kemenarikan konten \\
\hline & Kemenarikan isi atau materi \\
\hline & Proporsi objek video \\
\hline & $\begin{array}{l}\text { Legibiltas tampilan video virtual } 360 \\
\text { derajat }\end{array}$ \\
\hline
\end{tabular}

\section{Teknis Analisis Data}

Tujuan analisis dalam penelitian ini untuk mengkaji data respon mahasiswa dan hasil belajar. Pengkajian terhadap kedua data tersebut memiliki fungsi krusial (Van der Kleij et al., 2015). Hasil analisis data respon mahasiswa digunakan sebagai acuan untuk perbaikan substansi maupu tampilan video virtual. Hasil analisis data hasil belajar digunakan sebagai acuan penilaian objektivitas performa produk (daya dukung aplikasi hasil pengembangan ini terhadap pencapaian 
ketuntasan belajar mahasiswa) (Suryawati \& Osman, 2018).

Hasil skala perhitungan juga dilakukan dengan cara persentase (\%). Aspek atau komponen yang akan dianalisis terdiri dari: 1) materi, 2) bahasa, dan 3) penyajian. Hasil tanggapan mahasiswa diolah dengan menggunakan rumus persentase berikut:

$$
\text { Persentase }=\frac{\left.\sum \text { (keseluruhan skor jawaban angket }\right)}{\begin{array}{c}
n \times \text { bobot item } \times \text { jumlah responden } \\
\times 100 \%
\end{array}}
$$

Sumber: Sugiyono (2008)

Keterangan:

$\mathrm{n}=$ jumlah seluruh item angket

Jawaban setiap item instrumen pengembangan mempunyai gradasi dari tidak efektif sampai sangat efektif, misalnya diwakilkan dengan kata-kata pada tabel 3 dibawah:

\section{Tabel 3 Jawaban Item Instrumen}

\begin{tabular}{ll}
\hline Kriteria & Skor \\
\hline Sangat kurang & 1 \\
\hline Kurang & 2 \\
\hline Baik & 3 \\
\hline Sangat baik & 4 \\
\hline
\end{tabular}

Skor untuk setiap item sesuai dengan gradasi pilihan jawaban oleh responden dalam instrumen yang disebarkan. Instrumen penelitian menggunakan skala likert dibuat dalam bentuk checklist atau pilhan ganda (Sugiono: 2008). Dengan kriteria hasil pengambilan keputusan pada tabel 4 dibawah:

\section{Tabel 4 Pengambilan Keputusan Revisi Video Virtual 360 derajat laboratorium geografi}

\begin{tabular}{lll}
\hline $\begin{array}{l}\text { Tingkat } \\
\text { Pencapaian }\end{array}$ & Kualifikasi & Keterangan \\
\hline $86 \%-100 \%$ & Sangat Efisien & Tidak Perlu Revisi \\
\hline $71 \%-85 \%$ & Efisien & Tidak Perlu Revisi \\
\hline $56 \%-70 \%$ & Cukup Efisien & Revisi \\
\hline $41 \%-55 \%$ & Kurang Efisien & Revisi \\
\hline $0 \%-40 \%$ & Sangat Kurang Efisien & Revisi
\end{tabular}

Sumber: BSNP (Depdiknas), 2006.

\section{Luaran Penelitian}

Luaran dalam penelitian ini adalah video virtual 360 derajad yang berisi view lokasi penelitian (pantai malang selatan), lokasi penelitian yang diperoleh dari citra satelit google earth, pengukuran lapangan dan pengolahan data lapangan, 1 artikel yang diterbitkan pada Jurnal Nasional minimal Sinta 4, 1 kali presentasi di forum ilmiah nasional, dan HKI.

\section{HASIL DAN PEMBAHASAN}

Hasil pengembangan video virtual 360 sesuai dengan tahapan pengembangannya (Dick \& Carey, 2009) sebagai berikut:

\section{A. Analisis}

1. Analisis Kurikulum. Pada tahap ini, dilakukan tinjauan terhadap kurikulum berdasarkan silabus mata kuliah kerja lapangan. Berdasarkan hasil analisis kurikulum maka kompetensi dasar pada mata kuliah kerja lapangan yang dituangkan dalam pembuatan media video virtual 360 (Giacomone et al., 2018).

2. Analisis tujuan (identify intructional goals). Berdasarkan hasil analisis materi maka cakupan materi yang disampaikan melalui media video virtual 360 ini adalah view pantai, penentuan lokasi pantai, pembacaan instrument pengukuran, dan melakukan pengukuran untuk evaluasi pantai (Huamantinco Cisneros et al., 2016).

3. Perumusan menganalisis pembelajaran perkuliahan (conduct instructional analysis). Rumusan tujuan perkuliahan adalah sebagai berikut:

a. Mahasiswa dapat menjelaskan dengan video virtual 360 untuk melaksanakan praktikum lapangan secara virtual melalui video.

b. Mahasiswa dapat menentukan dengan tepat penentuan lokasi pantai, pengukuran lapangan dan pengolahan data lapangan yang tersusun rapi di melalui video virtual 360 .

c. Mahasiswa dapat membedakan teknik melakukan pengukuran untuk evaluasi pantai melalui video virtual 360 .

\section{B. Desain}

Tahap ini berisi pendesainan develop and select materials (mengembangkan dan memilih materi pembelajaran) dan design and conduct formative evaluation of instruction (merancang dan melaksanakan evaluasi formatif 
pembelajaran) yang dimulai dari alur pengambilan gambar video. Tahap ini bertujuan untuk memperoleh gambaran tentang bentuk dan apa saja yang ditampilkan pada video 360. Desain terdiri dari tampilan video memiliki konten utama dan konten pendukung. Menu konten video terdiri dari kompetensi dasar, materi yang di dalamnya terdapat pada konten video (Komalasari \& Rahmat, 2019).

Pada tahap desain konten video ini dibuat skrip terlebih dahulu yang merupakan gambaran keseluruhan alur (flow) dari media video virtual laboratory yang akan di buat. Alur konten dengan tampilan kemenarikan konten, kemenarikan isi atau materi, proporsi objek video dan legibiltas tampilan video virtual 360 derajat. Tahap selanjutnya adalah membuat storyboard. Pada tahap desain ini menghasilkan prototype media video virtual 360. Perancangan Video menurut ANG et al., (2018) beberapa konsep yang dirancang, yaitu a) Konsep Desain, b) Konsep Media, c) Konsep Naskah.

Target audience ditujukan untuk mahasiswa. Video pembelajaran ini bertujuan untuk pendidikan. Konsep media dilakukan untuk menyimpan hasil jadi video, yaitu $\mathrm{CD}$ yang diberi label disertai tempat/kotak CD yang diberi cover sesuai dengan materi yang dijelaskan pada video. Shooting script merupakan naskah video/film yang berisi uraian lengkap setiap adegan (shot), babak (scene), jenis musik, efek suara (sound effects) hubungan antara gambar dan suara, sudut pengambilan kamera, jenis shot, lokasi/ruang, sumber visual dan pemain sehingga akan mempermudah pelaksanaan dalam proses produksi. Hasil dari penulisan shooting script digunakan sebagai pedoman atau arahan dalam proses pembuatan film/video agar hasilnya lebih terstruktur.

\section{Evaluasi}

Tahap ini berisi revise instruction (merevisi pembelajaran) dan design and conduct summative evaluation (mendesain dan melakukan evaluasi sumatif). Pelaksanaan validasi media video virtual 360 dilakukan oleh 2 orang validator ahli. Kedua orang ahli media merupakan dosen. Hasil validasi dari kedua ahli dapat dilihat pada tabel 5 dibawah.

Tabel 5 Rekapitulasi Hasil Validasi Video Virtual 360

\begin{tabular}{|c|c|c|c|c|c|}
\hline \multirow[t]{4}{*}{ Format } & $\begin{array}{l}\text { Kesesuaian dan } \\
\text { keterpaduan warna } \\
\text { background dan } \\
\text { desain pada video } \\
\text { virtual } 360 \\
\end{array}$ & 3 & 3 & 3 & 2.9 \\
\hline & $\begin{array}{l}\text { Kejelasan gambar } \\
\text { pada video virtual } \\
360\end{array}$ & 3 & 3 & 3 & \\
\hline & $\begin{array}{l}\text { Kejelasan animasi } \\
\text { pada video virtual } \\
360\end{array}$ & 2 & 4 & 3 & \\
\hline & $\begin{array}{l}\text { Kejelasan tulisan } \\
\text { pada video virtual } \\
360\end{array}$ & 3 & 2 & 2.5 & \\
\hline \multirow[t]{6}{*}{ Isi } & $\begin{array}{l}\text { Video virtual } 360 \\
\text { dapat digunakan } \\
\text { untuk mencapai } \\
\text { tujuan pembelajaran }\end{array}$ & 2 & 4 & 3 & 3.1 \\
\hline & $\begin{array}{l}\text { Konsep dalam video } \\
\text { virtual } 360 \text { sesuai } \\
\text { dengan Kompetensi } \\
\text { Dasar (KD) }\end{array}$ & 3 & 4 & 3.5 & \\
\hline & $\begin{array}{l}\text { Video virtual } 360 \\
\text { dapat menjelaskan } \\
\text { konsep geografi }\end{array}$ & 2 & 4 & 3 & \\
\hline & $\begin{array}{l}\text { Video virtual } 360 \\
\text { membantu } \\
\text { mahasiswa dalam } \\
\text { melakukan } \\
\text { praktikum geografi }\end{array}$ & 2 & 4 & 3 & \\
\hline & $\begin{array}{l}\text { Video virtual } 360 \\
\text { membantu } \\
\text { mahasiswa dalam } \\
\text { memahami sub } \\
\text { materi geografi }\end{array}$ & 3 & 3 & 3 & \\
\hline & $\begin{array}{l}\text { Informasi yang } \\
\text { disajikan akurat dan } \\
\text { terbaru }\end{array}$ & 3 & 3 & 3 & \\
\hline \multirow[t]{2}{*}{ Bahasa } & $\begin{array}{l}\text { Kosakata yang } \\
\text { digunakan mudah } \\
\text { dipahami dan sesuai } \\
\text { dengan tingkat } \\
\text { perkembangan usia }\end{array}$ & 3 & 3 & 3 & 3 \\
\hline & $\begin{array}{l}\text { Bahasa yang di } \\
\text { gunakan bebas } \\
\text { makna ambigu }\end{array}$ & 3 & 4 & 3 & \\
\hline Praktisi & $\begin{array}{l}\text { Fasilitas pendukung } \\
\text { dalam pemakaian } \\
\text { video virtual } 360 \\
\text { dapat digunakan } \\
\text { oleh mahasiswa }\end{array}$ & 3 & 4 & 3.5 & 3.5 \\
\hline
\end{tabular}




\begin{tabular}{llllll}
\hline Efektif & $\begin{array}{l}\text { Meningkatkan rasa } \\
\text { ingin tahu dan minat } \\
\text { belajar mahasiswa }\end{array}$ & 3 & 4 & 3.5 & 3.4 \\
& $\begin{array}{l}\text { Ketahanan } \\
\text { pemakaian video } \\
\text { virtual 360 }\end{array}$ & 4 & 4 & 4 & \\
& $\begin{array}{l}\text { Keefektifan video } \\
\text { virtual 360 terhadap } \\
\text { waktu belajar }\end{array}$ & 3 & 4 & 3.5 & \\
& $\begin{array}{l}\text { Video virtual 360 } \\
\text { dapat meningkatkan } \\
\text { partisipasi dan } \\
\text { keterlibatan } \\
\text { mahasiswa dalam } \\
\text { kegiatan belajar }\end{array}$ & 2 & 3 & 2.5 & \\
\hline $\begin{array}{l}\text { Penggunaan video } \\
\text { virtual 360 untuk } \\
\text { perorangan maupun } \\
\text { kelompok }\end{array}$ & 3 & & & & \\
\hline Jumlah Skor & & & \\
\hline Rata-rata Validator & & & 3.5 & \\
\hline
\end{tabular}

Keterangan:

$\mathrm{Ki} \quad$ : Rata rata tiap kriteria

$\mathrm{Ai} \quad$ : Rata rata tiap aspek

RTV : Rata rata total validasi

Keterangan:

$\mathrm{X}=$ responden ahli desain

$\mathrm{X}_{\mathrm{i}}=$ jumlah skor ideal dalam satu item

$\%=$ konstanta

Dari penilaian data ahli desain tersebut, maka dapat dilakukan perhitungan untuk keseluruhan item/aspek sebagai berikut:

$$
\begin{aligned}
\mathrm{Vd} & =\frac{\sum x n}{\sum x i} \times 100 \% \\
\mathrm{Vd} & =\frac{56,5}{72} \times 100 \%=78,5 \%
\end{aligned}
$$

Berdasarkan hasil validasi ahli desain diperoleh nilai kevalidan mencapai $78,5 \%$ hal tersebut masuk dalam Kriteria $(71 \%-85 \%)$ dan masuk dalam kriteria valid dan layak digunakan untuk pembelajaran di kelas tidak perlu revisi. Adapun kriteria dapat dijelaskan tabel 6 dibawah:

Tabel 6 Kriteria Validasi

\begin{tabular}{|l|l|l|}
\hline $\begin{array}{l}\text { Tingkat } \\
\text { Pencapaian }\end{array}$ & Kualifikasi & Keterangan \\
\hline $86 \%-100 \%$ & Sangat Efisien & Tidak Perlu Revisi \\
\hline $\mathbf{7 1 \% - 8 5 \%}$ & Efisien & Tidak Perlu Revisi \\
\hline $56 \%-70 \%$ & Cukup Efisien & Revisi \\
\hline $41 \%-55 \%$ & Kurang Efisien & Revisi \\
\hline $0 \%-40 \%$ & $\begin{array}{l}\text { Sangat Kurang } \\
\text { Efisien }\end{array}$ & Revisi \\
\hline
\end{tabular}

Revisi dilakukan pada media video virtual 360 sesuai saran dan masukan dari validator ahli media dan materi. Revisi dilakukan terutama pada 3.bagian materi yang disampaikan masih sedikit, beberapa bahasa kurang baku, kurang materi untuk bahan diskusi dan kemasan sampul yang kurang menarik dan format dan isi. Pengembangan media yang dilakukan dengan 4 tahapan ini, meliputi tahap analisis, desain, evaluasi dan revisi. Implementasi media (berupa prototype) di lakukan pada kelompok kecil. Berdasarkan hasil pengembangan media pada tahap evaluasi media video virtual 360 dikategorikan valid dengan rata-rata total validasi (RTV) 3,18. Kategori valid tergambar dari hasil penilaian validator, dimana validator media dan materi menyatakan baik berdasarkan konten (sesuai kurikulum, dan materi) dan konstruk (sesuai dengan kaidah). Praktis tergambar dari 3.18 18 sil uji coba, dimana semua mahasiswa dapat menggunakan media video virtual 360 dengan baik dan efektif.

Rata-rata total aspek isi, bahasa, praktis dan efektivitas dikategorikan valid dengan nilai masing masing masing 3,1 (valid); 3 (valid); 3,5 (valid) dan 3,4 (valid). Namun untuk format rata rata total aspek dikategorikan cukup valid $(2,9)$. Rata-rata total validasi media yaitu 3.18 (valid) yang berarti media video virtual 360 dapat digunakan untuk uji coba pada kelompok kecil. Validasi video virtual 360 dilakukan untuk mengetahui kelayakan atau kevalidan media terhadap pembelajaran. Validasi dilakukan oleh 2 orang validator yaitu 1 orang ahli media dan 1 orang ahli materi. Pada lembar validasi video virtual 360 terdapat 5 aspek yang digunakan untuk menguji layak atau tidak video virtual 360 digunakan, yaitu aspek format, aspek isi, bahasa, praktis dan efektif. Aspek ini dikembangkan dan dimodifikasi dari lembar validasi media (Yamasari, 2010).

Validator menilai video virtual 360 memiliki kelebihan sebagai media yang dapat membantu mahasiswa dalam memahami materi yang disajikan dalam bentuk video ini dapat mengefektifkan waktu pembelajaran, karena simulasi dalam video virtual 360 hanya memerlukan waktu sepanjang durasi video. Hal ini sesuai dengan pendapat Asyhar (2012), kelebihan virtual laboratory, antara lain 1) tidak memerlukan peralatan laboratorium dan bahanbahan yang harganya mahal, sehingga dapat menjadi alternatif mengatasi keterbatasan atau ketiadaan fasilitas alat dan bahan laboratorium, 2) mengurangi keterbatasan waktu, jika tidak ada cukup waktu untuk mengajari di dalam laboratorium hingga mereka paham. Sehingga efektif membantu peserta didik yang lambat dan 
dapat memacu efektivitas belajar bagi yang lebih cepat. Selain itu media ini dinilai bersifat interaktif, sehingga peserta didik dapat melakukan praktikum sebagaimana yang dilakukan pada laboratorium fisik dengan visual yang menarik. Peserta didik juga dapat menggunakan secara sendiri-sendiri atau berkelompok dan tidak mesti di ruang laboratorium.

Namun demikian, validator ahli juga menilai terdapat beberapa kelemahan pada media video virtual 360 terutama pada aspek format dan isi. Validator ahli menyarankan agar dilakukan penambahan penggunaan alat perekam audio untuk memperjelas proses pelaksanaan materi. Dalam pelaksanaan praktikum agar diberikan keterangan yang jelas tentang hal-hal yang boleh dilakukan maupun yang tidak boleh dikerjakan oleh praktikan. Selain itu diharapkan menambah materi pembeljaran yang lebih luas, agar memiliki bahan yang bisa digunakan untuk berdiskusi.

Hal tersebut menunjukkan berdasarkan hasil uji coba pada kelompok kecil bahwa materi yang di sampaikan dengan media video virtual 360 lebih mudah dipahami. Pemahaman mahasiswa terutama pada pengetahuan konseptual dan prosedural. Media pembelajaran video virtual 360 ini berfungsi manipulatif. Menurut Asyhar (2012), fungsi manipulatif pada media karena terkait dengan simulasi yang terdapat dalam media ini mampu menampilkan benda-benda atau situasi yang menggambarkan benda atau situasi sebenarnya. Simulasi praktikum penanaman bakteri dan evaluasi di sampaikan secara interaktif karena mahasiswa dapat terlibat langsung mengoperasikan media tersebut disesuaikan dengan kecepatan belajar mahasiswa masing-masing. Keterlibatan mahasiswa secara aktif dalam kegiatan simulasi tersebut menyebabkan mahasiswa dapat membangun pengetahuannya sendiri. Hal tersebut sejalan dengan pendapat Rousse dalam Sardiman (2011) bahwa segala pengetahuan harus diperoleh dengan pengamatan sendiri, pengalaman sendiri, penyelidikan sendiri dengan bekerja sendiri, dengan fasilitas yang diciptakan sendiri baik secara rohani maupun teknis.

\section{SIMPULAN}

Simpulan dari penelitian ini adalah pengembangan video virtual 360 berbasis multimedia interaktif pada sub materi geografi pantai dilakukan melalui empat tahapan: analisis, disain, evaluasi dan revisi. Dan ditinjau dari rata rata total validasi ahli media dan materi video virtual 360 berbasis multimedia interaktif dinilai hasil validasi ahli desain diperoleh nilai kevalidan mencapai 78,5\% hal tersebut masuk dalam kriteria (71\% - 85\%) dan masuk dalam kriteria valid dan layak digunakan untuk pembelajaran di kelas tidak perlu revisi.

\section{DAFTAR PUSTAKA}

Almazyad, R., \& Alqarawy, M. (2020). The Design of Dick and Carey Model. Society for Information Technology \& ....

ANG, W. Y., HERYANI, N., LAD, S. T. L., \& LAU, Y. (2018). Evaluation of a fall prevention educational video on fall risk awareness, knowledge and help seeking behaviour among surgical patients. Singapore Nursing Journal.

Argyriou, L., Economou, D., \& Bouki, V. (2020). Design methodology for $360^{\circ}$ immersive video applications: the case study of a cultural heritage virtual tour. Personal and Ubiquitous

Computing. https://doi.org/10.1007/s00779-020-013738

Bao, Y., Zhang, T., Pande, A., Wu, H., \& Liu, X. (2017). Motion-Prediction-Based Multicast for 360-Degree Video Transmissions. 2017 14th Annual IEEE International Conference on Sensing, Communication, and Networking, $\quad$ SECON 2017. https://doi.org/10.1109/SAHCN.2017.7964 928

Basse, R. M., Omrani, H., Charif, O., Gerber, P., \& Bódis, K. (2014). Land use changes modelling using advanced methods: Cellular automata and artificial neural networks. The spatial and explicit representation of land cover dynamics at the cross-border region scale. Applied Geography. https://doi.org/10.1016/j.apgeog.2014.06.01 6

Bastian, I., \& Idrus, O. (2019). Paradigma Baru Manajemen Pendidikan. Modul Universitas Terbuka.

Clayton, N. R., \& Abbass, H. (2019). Machine Teaching in Hierarchical Genetic Reinforcement Learning: Curriculum Design of Reward Functions for Swarm Shepherding. 2019 IEEE Congress on 
Evolutionary Computation, CEC 2019 Proceedings.

https://doi.org/10.1109/CEC.2019.8790157

Ermila Hendriyani, M., \& Novi, R. (2020). LAPORAN PRAKTIKUM MANDIRI DALAM BENTUK VIDEO PRESENTASI UNTUK MENGEMBANGKAN KREATIVITAS DAN KOMUNIKASI LISAN DI MASA PANDEMI COVID-19. Prosiding Seminar Nasional Pendidikan FKIP Universitas Sultan Ageng Tirtayasa.

Friedman, A., \& Schneider, E. (2018). Developing a Visualization Education Curriculum in the Age of Big Data Using the Dick and Carey Model. Visual Communication Quarterly. https://doi.org/10.1080/15551393.2018.153 0115

Giacomone, B., Godino, J. D., \& Beltrán-Pellicer, P. (2018). Developing the prospective mathematics teachers' didactical suitability analysis competence. Educacao e Pesquisa. https://doi.org/10.1590/S16784634201844172011

Hagerstrand, T. (2019). The domain of human geography. In Directions in Geography. https://doi.org/10.4324/9780429273292-4

Hamilton, D., McKechnie, J., Edgerton, E., \& Wilson, C. (2021). Immersive virtual reality as a pedagogical tool in education: a systematic literature review of quantitative learning outcomes and experimental design. Journal of Computers in Education. https://doi.org/10.1007/s40692-020-001692

Huamantinco Cisneros, M. A., Revollo Sarmiento, N. V., Delrieux, C. A., Piccolo, M. C., \& Perillo, G. M. E. (2016). Beach carrying capacity assessment through image processing tools for coastal management. Ocean and Coastal Management. https://doi.org/10.1016/j.ocecoaman.2016.0 6.010

Kantamneni, N. (2020). The impact of the COVID-19 pandemic on marginalized populations in the United States: A research agenda. In Journal of Vocational Behavior. https://doi.org/10.1016/j.jvb.2020.103439
Komalasari, K., \& Rahmat. (2019). Living values based interactive multimedia in Civic Education learning. International Journal of Instruction.

https://doi.org/10.29333/iji.2019.1218a

Kusumaningsih, Y.R, Iswahyudi, C., \& Susanti, E. (2014). Pengembangan Model Laboratorium Virtual Sebagai Solusi Keterbatasan Sumber daya Pembelajaran. Prossiding Seminar Nassional Aplikasi Sains \& Teknologi (SNAST).

Lee, B., Riche, N. H., Isenberg, P., \& Carpendale, S. (2015). More Than Telling a Story: Transforming Data into Visually Shared Stories. IEEE Computer Graphics and Applications.

https://doi.org/10.1109/MCG.2015.99

Lièvre, A., Turpin, A., Ray-Coquard, I., Le Malicot, K., Thariat, J., Ahle, G., Neuzillet, C., Paoletti, X., Bouché, O., Aldabbagh, K., Michel, P., Debieuvre, D., Canellas, A., Wislez, M., Laurent, L., Mabro, M., Colle, R., Hardy-Bessard, A. C., Mansi, L., ... Bernichon, E. (2020). Risk factors for Coronavirus Disease 2019 (COVID-19) severity and mortality among solid cancer patients and impact of the disease on anticancer treatment: A French nationwide cohort study (GCO-002 CACOVID-19). European Journal of Cancer. https://doi.org/10.1016/j.ejca.2020.09.035

Martanti, R. D., \& Winarni, S. (2020). Gymnastics Multimedia Learning Development for Physical Education. https://doi.org/10.5220/0009214601280135

Mastuty, R. (2020). TEACHING FROM HOME: dari Belajar Merdeka menuju Merdeka Belajar. In Yayasan Kita Menulis.

Molenda, M. (2015). In Search of the Elusive ADDIE Model. Performance Improvement. https://doi.org/10.1002/pfi.21461

Putra, R. A. M. (2020). Kendala Pelaksanaan Pembelajaran Jarak Jauh (PJJ) dalam Masa Pandemi. Journal of Physics A: Mathematical and Theoretical.

Ramdani, A., Jufri, A. W., \& Jamaluddin, J. 
(2020). Pengembangan Media Pembelajaran Berbasis Android pada Masa Pandemi Covid-19 untuk Meningkatkan Literasi Sains Peserta Didik. Jurnal Kependidikan: Jurnal Hasil Penelitian Dan Kajian Kepustakaan Di Bidang Pendidikan, Pengajaran Dan Pembelajaran. https://doi.org/10.33394/jk.v6i3.2924

Rosita, I., \& Leonard, L. (2015). Meningkatkan Kerja Sama Siswa Melalui Pembelajaran Kooperatif Tipe Think Pair Share. Formatif: Jurnal Ilmiah Pendidikan MIPA. https://doi.org/10.30998/formatif.v3i1.108

Sapri, J., Agustriana, N., \& Kusumah, R. G. T. (2019). The Application of Dick and Carey Learning Design toward Student's Independence and Learning Outcome. https://doi.org/10.2991/icetep-18.2019.53

Suryawati, E., \& Osman, K. (2018). Contextual learning: Innovative approach towards the development of students' scientific attitude and natural science performance. Eurasia Journal of Mathematics, Science and Technology Education. https://doi.org/10.12973/ejmste/79329

Van der Kleij, F. M., Feskens, R. C. W., \& Eggen, T. J. H. M. (2015). Effects of Feedback in a Computer-Based Learning Environment on Students' Learning Outcomes: A MetaAnalysis. Review of Educational Research. https://doi.org/10.3102/0034654314564881

Yamasari, Y. (2010). Pengembangan media pembelajaran matematika berbasis ICT yang berkualitas. Seminar Nasional Pascasarjana.

Yusuf, I., Widyaningsih, W., \& Purwati, D. (2015). Pengembangan Perangkat Pembelajaran Fisika Modern Berbasis Media Laboratorium Virtual Berdasarkan. Pancaran.

Zikky, M., Susanto, D., \& Ramadhi, I. (2020). Media Pembelajaran Interaktif Jarak Jauh Untuk Laboratorium Video Broadcasting Berbasis Virtual Reality Kolaboratif. JST (Jurnal Sains Terapan). https://doi.org/10.32487/jst.v6i2.941 